Check for updates

Cite this: RSC Adv., 2019, 9, 37365

Received 12th September 2019 Accepted 28th October 2019

DOI: $10.1039 / c 9 r a 08675 g$

rsc.li/rsc-advances

\title{
Near-infrared (NIR) surface-enhanced Raman spectroscopy (SERS) study of novel functional phenothiazines for potential use in dye sensitized solar cells (DSSC) $\uparrow$
}

\author{
Bastian Moll, $\ddagger^{\mathrm{a}}$ Thomas Tichelkamp, $\$^{\mathrm{b}}$ Susann Wegner, ${ }^{\mathrm{a}}$ Biju Francis, ${ }^{\mathrm{D}}{ }^{\mathrm{a}}$ \\ Thomas J. J. Müller (D) ${ }^{* b}$ and Christoph Janiak (D) *a
}

\begin{abstract}
Phenothiazines are of potential use as dye sensitizers in Grätzel-type dye sensitized solar cells (DSSC). Plasmonic nanoparticles like gold nanoparticles can enhance the power conversion efficiency of these solar cells. In this work near-infrared surface-enhanced Raman spectroscopy (NIR-SERS) is used to investigate the interaction between six novel phenothiazine-merocyanine dyes containing the three different functional groups rhodanine, 1,3-indanedione and cyanoacylic acid with plasmonic nanomaterials, to decide if the incorporation of plasmonic nanoparticles could enhance the efficiency of a Grätzel-type solar cell. The studies were carried out in the solution state using spherical and rodshaped gold nanostructures. With $\mathrm{KCl}$ induced agglomerated spherical gold nanoparticles, forming SERS hot spots, the results showed low detection limits between $0.1 \mu \mathrm{mol} \mathrm{L} \mathrm{L}^{-1}$ for rhodanine containing phenothiazine dyes, because of the formation of $\mathrm{Au}-\mathrm{S}$ bonds and $3 \mu \mathrm{mol} \mathrm{L} \mathrm{L}^{-1}$ for cyanoacrylic acid containing dyes, which formed $\mathrm{H}$-aggregates in the watery dispersion. Results with gold nanorods showed similar trends in the SERS measurements with lower limits of detection, because of a shielding effect from the strongly-bound surfactant. Additional fluorescence studies were carried out to determine if the incorporation of nanostructures leads to fluorescence quenching. Overall we conclude that the addition of gold nanoparticles to rhodanine and 1,3-indanedione containing phenothiazine merocyanine dyes could enhance their performance in Grätzel-type solar cells, because of their strong interactions with plasmonic nanoparticles.
\end{abstract}

\section{Introduction}

Phenothiazines, dibenzo anellated 1,4-thiazines, ${ }^{1}$ are a particularly interesting class of functional organic molecules with a broad spectrum of applications ranging from pharmaceuticals to redox probes to functional chromophores. Their use as pharmaceuticals (Fig. 1) encompasses antihistaminics, ${ }^{2}$ sedatives, anxiolytic agents, psychotropic drugs, ${ }^{3,4}$ as well as antioxidants for the treatment of neurodegenerative diseases. ${ }^{5}$ In addition, methylene blue, a phenothiazine derivative, has been revealed as an active agent against Alzheimer's disease. ${ }^{6}$ While toxicity for humans is low, high toxicity for insects, bacteria and fungi has favored the use of phenothiazines as insecticides,

${ }^{a}$ Institut für Anorganische Chemie und Strukturchemie, Heinrich-Heine-Universität, D-40204 Düsseldorf, Germany. E-mail: janiak@uni-duesseldorf.de

${ }^{b}$ Institut für Organische Chemie und Makromolekulare Chemie, Heinrich-HeineUniversität, D-40204 Düsseldorf, Germany.E-mail:ThomasJJ.Mueller@hhu.de $\dagger$ Electronic supplementary information (ESI) available: Au-NP and Au-NR synthesis, TEM images, Raman spectra of phenothiazines 2, 4 and 6. Fluorescence spectra after addition of water. See DOI: 10.1039/c9ra08675g \$ These authors contributed equally. antibacterial, and antifungal agents. ${ }^{7,8}$ Also, the peculiar occurrence of both luminescence and redox activity has made phenothiazines and their oligomers particularly interesting as redox switchable luminophores, ${ }^{9}$ dye sensitizers in Grätzel-type solar cells, ${ }^{10}$ and as donors in photoinduced intramolecular electron transfer systems. ${ }^{11}$ Arylated and alkynylated phenothiazines $^{12}$ have been employed as redox-active monolayers on gold $^{13}$ or zinc and iron surfaces ${ }^{14}$ and the electronic and chemical properties of the phenothiazine backbone offer their

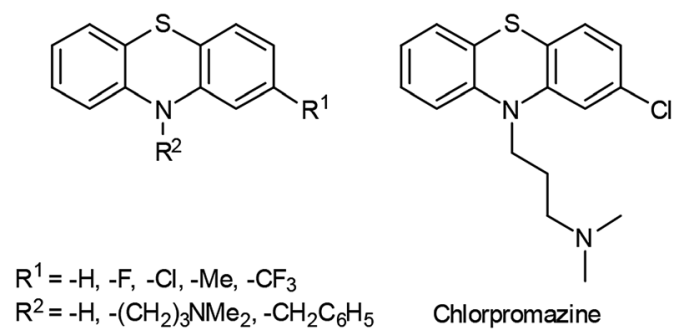

Fig. 1 Lead structure of many phenothiazine based pharmaceuticals and chlorpromazine as typical neuroleptic in the phenothiazine series. 
potential use as functional materials in Li-ion technology ${ }^{15}$ as well.

In the growing interest of renewable energies, organic photovoltaics are an attractive interest of research, because they are believed to possess the potential to be low cost manufactured with high power conversion efficiencies (PCE). ${ }^{16}$ In 1991 O'Reagan and Grätzel presented the first concept of a dyesensitized solar cell (DSSC). ${ }^{17}$ In a typical DSSC a sintered mesoporous oxide layer, mostly $\mathrm{TiO}_{2}$, ensures electronic conductivity. Attached to this nanocrystalline layer, a monolayer of a charge transfer dye acts as an absorber. Most conveniently iodide/triiodide as a redox-active electrolyte warrants the regeneration of the oxidized dye, ${ }^{18}$ and a platinum coated glass surface is used as the cathode to complete the photocurrent circuit. $^{19}$ First dye sensitizers mostly contained ruthenium complexes as dyes, such as dye N3, a cis-RuL ${ }_{2}(\mathrm{NCS})_{2}$ complex introduced by Grätzel et al. in 1993. ${ }^{20}$

Since then a wide variety of metal-based and metal-free dyes were investigated, ${ }^{21}$ including phenothiazines ${ }^{22}$ and phenothiazine merocyanines. ${ }^{10 b}$ Since 1991 much effort was put in enhancing the efficiency of dye sensitized solar cells by optimizing dyes, electrolytes and all other components of the solar cells. ${ }^{23}$ Furthermore, light absorption in the solar cell can be increased. An option is the use of plasmonic nanoparticles, such as gold or silver nanoparticles. ${ }^{24}$ Other plasmonic nanostructures like nanorods were also tested for enhancing the light absorption. ${ }^{25}$

Plasmonic nanoparticles increase photocurrents of DSSCs taking advantage of the localized surface plasmon resonance (LSPR) as nano antennae. A similar effect is surface-enhanced Raman scattering (SERS). ${ }^{26,27}$ The LSPR enhances photocurrents through excitation of electrons in dyes (HOMO-LUMO transition). ${ }^{26}$ Since its first observation in 1973 by Fleischmann et $a{ }^{28}$ and the discovery of single-molecule detection by Nie et $a .^{29}$ and Kneipp et al., ${ }^{30}$ SERS turned out to be a highly sensitive spectroscopic method, ${ }^{31,32}$ used for the detection of explosives $^{33}$ and even bacteria, ${ }^{34}$ as documented in numerous publications. Likewise a highly sensitive spectroscopic tool offers great potential for drug detection. ${ }^{35,36}$ Key to this spectroscopic method is the presence of coinage metal nanoparticles, preferentially gold and silver, ${ }^{37}$ but copper is also an applicable SERS substrate. ${ }^{38,39}$ Their LSPR, ${ }^{40}$ i.e. the induced oscillation of conduction electrons of the metal due to resonant laser excitation (Fig. 2a), induces a dipole with the angular frequency $\omega_{\text {inc }}$ which emits radiation as a resonant elastic scattering off the metal sphere. ${ }^{40}$ A molecule can interact with the local electric field near to the surface of a metal sphere and the outgoing field $\omega_{\text {inc }}-\omega_{\text {vib }}$ is able to excite a LSPR of metal nanoparticles, in which the intensity of the SERS effect depends on the incoming field $\omega_{\text {inc }}$ and the outgoing field (Fig. 2b). ${ }^{40}$

Very high enhancement factors can be obtained in localized regions between two or more particles. These spots are called "hot spots". In the absence of hot spots, the enhancement factor is limited to the order of $10^{3}$, whereas in sections between 1 and $5.5 \mathrm{~nm}$ the enhancement factor ranges around $10^{7}-10^{11} .^{40}$

In 2013 Tatsuma et al. reported an optimized enhancement of photocurrents in DSSCs in hot spots between nanoparticles,

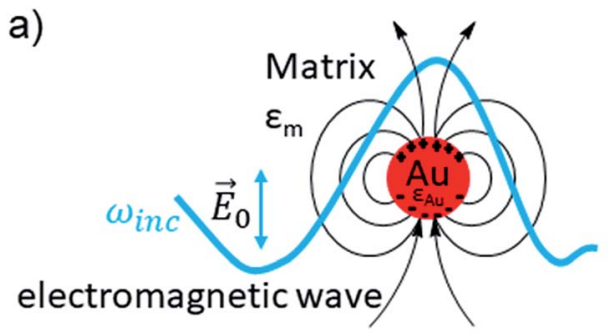

b)

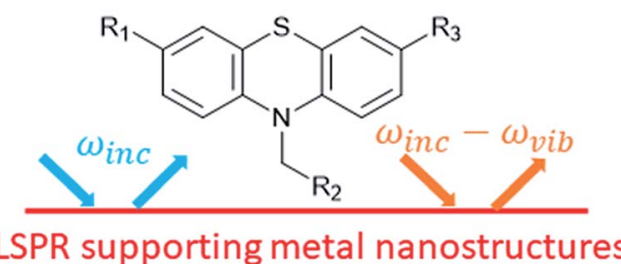

Fig. 2 Electromagnetic effects involved in Surface-EnhancedRaman-Scattering (SERS).

comparable to hot spots in surface-enhanced Raman spectroscopy. ${ }^{26}$ Incorporation of plasmonic nanoparticles in DSSC could enable elucidating SERS studies on solar cell dye characteristics and photocurrent enhancements. Also, forced agglomeration of the nanoparticles leading to hot spots, will lead to potential use in DSSC through the enhancement in SERS intensity.

Here we report SERS studies with a series of six novel intensively fluorescent phenothiazine push-pull chromophores (Fig. 3) directed to investigate the potential utility of these dyes in enhanced DSSC plasmonic nanomaterials. The phenothiazine luminophores are divided into three subgroups: Phenothiazine dyes (PD) 1 and $\mathbf{2}$ bear a rhodanine group, PD 3 and 4 a 1,3-indanedione group, while dyes 5 and $\mathbf{6}$ possess

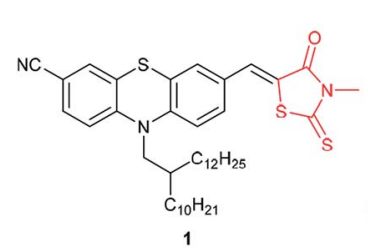

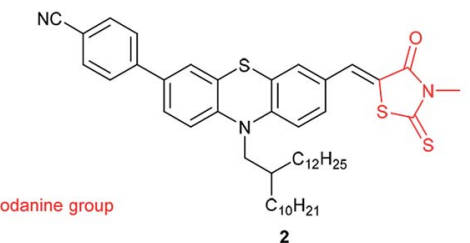

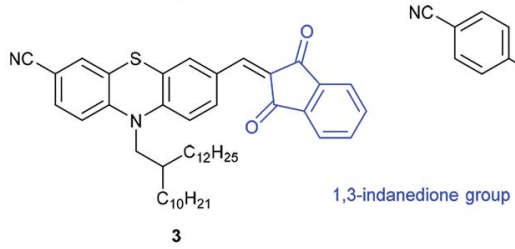

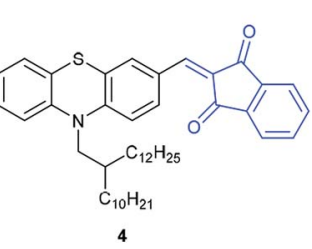

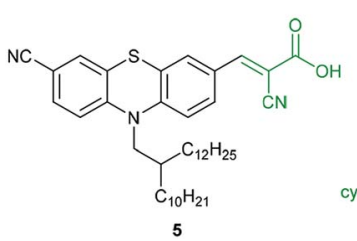
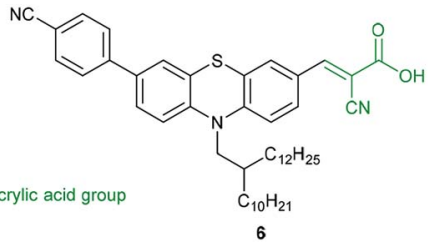

Fig. 3 Phenothiazine dyes (PD) 1-6 used in this work for quantification through the SERS effect. 
a cyanoacrylic acid functionality (for their preparation, see ESI $\dagger$ ). Solutions of all six phenothiazines were examined by Raman spectroscopy in the presence of spherical gold nanoparticles (Au-NP) and gold nanorods (Au-NR) for assessing the SERS effect.

\section{Experimental}

\section{Chemicals}

All chemicals, whose syntheses are not described in this work, were obtained commercially: potassium tetrachloroaurate from chemPUR, dopamine hydrochloride, cetyltrimethylammonium bromide and trisodium citrate from Alfa Aesar, sodium borohydride from J. T. Baker. All chemicals were analysis or HPLCgrade and used without further purification. Ultrapure water was generated by a Merck Millipore Synergy ${ }^{\circledR}$ instrument. The phenothiazines 1-6 were synthesized in analogy to related phenothiazinyl merocyanines (see ESI $\dagger$ ). ${ }^{9 a, 10 b}$

\section{Instrumentation}

UV/Vis spectra were measured with a Shimadzu UV-2450 (190$900 \mathrm{~nm}$ ) and an Analytik Jena Specord S 600 (190-1100 nm). Near-infrared absorption measurements were carried out using a PerkinElmer UV/Vis/NIR Spectrometer Lambda 19. Fluorescence spectra were obtained using a Hitachi F-7000 spectrophotometer. Excitation wavelengths were determined through UV/Vis spectroscopy. Fluorescence cuvettes, made of quartz glass, were used. Raman spectra were collected using a Bruker MultiRAM with a Nd:YAG-laser (wavelength $1064 \mathrm{~nm}$ ). All samples were measured with comparable settings. The Raman spectra of pure phenothiazines were measured in the solid state. SERS spectra were obtained in solution/dispersion with 200-700 mW laser power, 250 scans and an aperture width of $4 \mathrm{~mm}$. After addition of phenothiazine solution to the nanomaterial dispersion about $0.2 \mathrm{~mL}$ of the mixture was placed into an NMR tube and the Raman spectrum was recorded immediately. Only laser intensities were varied, depending on the signal intensities. The Raman instrument used in this work, intentionally made use of an NIR laser with an excitation wavelength of $1064 \mathrm{~nm}$ coupled with an FT-Raman spectrometer. This instrument setting is generally used to minimize fluorescence background in Raman spectroscopy. The excitation wavelength in the near-infrared is used because in general it does not provide enough energy to excite molecules to higher electronic states which is required for fluorescence relaxation. Measurements within the near-infrared wavelength of 780$1064 \mathrm{~nm}$ are of great importance. With this excitation wavelength, the excitation of fluorescence is minimized or excluded, which otherwise can interfere with the Raman signals. So for NIR- and IR-lasers higher intensities in the laser power are possible, without inducing "photobleaching" processes, which are photochemical reactions of a fluorophore that lead to a loss of fluorescence. ${ }^{41,42}$ The disadvantages of NIR-lasers are the dependence of the Raman intensity on the excitation wavelength which decreases with the factor $\lambda^{-4}$ (ref. 43) and the lower sensitivity towards near-infrared radiation of modern
CCD-detectors ${ }^{44}$ Thus, to obtain high SERS enhancements, it is important to excite the LSPR efficiently by matching it as best as possible with the excitation wavelength of the laser.

Transmission electron microscopy (TEM) images were obtained with a TECNAI G2 F20 from FEI at the "Ernst Ruska Zentrum für Mikroskopie und Spektroskopie mit Elektronen" in Jülich. The images were taken at room temperature with an acceleration voltage of $200 \mathrm{kV}$. For the measurements, the sample was deposited onto a carbon-coated copper grid (CF200$\mathrm{Cu}$ Mesh) and dried under air. For TEM-EDX (transmission electron microscopy-energy dispersive X-ray spectroscopy) the exposure time for individual EDX spectra was $3 \mathrm{~min}$. (The EDX analyses always showed traces of oxygen as a result of the preparation of the grids in air.)

\section{Synthesis of spherical gold nanoparticles}

Spherical gold nanoparticles (Au-NPs) were synthesized via the modified Turkevich route ${ }^{45}$ by microwave heating of $8 \mathrm{mg}(21.2$ $\mu \mathrm{mol}) \mathrm{KAuCl}_{4}$ and $10 \mathrm{mg}(38.8 \mu \mathrm{mol})$ trisodium citrate in Millipore water $(40 \mathrm{~mL}$ ) for $2 \mathrm{~min}$ (see ESI $\dagger$ for details). The TEM images showed an average particle diameter of $36 \pm 7 \mathrm{~nm}$ (see images and histogram in Fig. S1 ESI $\dagger$ ). In the UV/Vis spectrum a peak for the LSPR was observed at $525 \mathrm{~nm}$ (Fig. S3 ESI $\dagger$ ).

\section{Synthesis of gold nanorods}

Gold nanorods (Au-NRs) were prepared using a seedless synthesis with dopamine as a reducing agent, potassium tetrachloroaurate as a gold precursor and cetyltrimethylammonium bromide (CTAB) as a stabilising agent in aqueous solution (see ESI $\dagger$ for details). ${ }^{46}$ TEM analysis (Fig. S5 ESI $\dagger$ ) gave $89 \pm 13 \mathrm{~nm}$ for the nanorod length and $21 \pm 6 \mathrm{~nm}$ for the nanorod width (histogram in Fig. S5 in ESI $\dagger$ ).

The LSPR signal is visible at $542 \mathrm{~nm}$ (transversal axis) and $937 \mathrm{~nm}$ (longitudinal axis) in the UV/Vis spectrum (Fig. S6 $\dagger$ in ESI†).

\section{Phenothiazine stock solutions}

Stock solutions of the phenothiazines 1-6 with a concentration of $c=0.33 \mathrm{mM}$ were prepared by dissolving $3.3 \times 10^{-3} \mathrm{mmol}$ of the phenothiazines in $10 \mathrm{~mL}$ of acetone.

\section{Nanoparticle dispersions}

For spherical gold nanoparticles and gold nanorods the gold concentrations of the aqueous dispersions were $c=0.53 \mathrm{mM}$ $\left(0.1 \mathrm{~g} \mathrm{~L}^{-1}\right)$.

\section{Spherical gold nanoparticle-phenothiazine dispersions with $\mathrm{KCl}$}

$10 \mathrm{mg}(0.13 \mathrm{mmol})$ of solid $\mathrm{KCl}$ were dissolved in $1.5 \mathrm{~mL}$ of acetone (to give $c=0.04 \mathrm{mM}$ ) and then an aliquot of the phenothiazine stock solution was added: $30 \mu \mathrm{L}$ (to give $c$ (phenothiazine) $=3.24 \mu \mathrm{M}), 10 \mu \mathrm{L}$ (to give $c$ (phenothiazine) $=$ $1.11 \mu \mathrm{M}$ ) or $1 \mu \mathrm{L}$ (to yield $c$ (phenothiazine) $=0.11 \mu \mathrm{M}$ ) of phenothiazine in the final solution. Then $1.5 \mathrm{~mL}$ of the nanoparticle dispersion was added to the solution and thoroughly 
mixed. About $0.2 \mathrm{~mL}$ of the mixture was placed into an NMR tube and the Raman spectrum was recorded immediately. (Less suitable gold nanoparticle-phenothiazine dispersions without $\mathrm{KCl}$ were prepared with the same stoichiometries but no $\mathrm{KCl}$ added.)

\section{Gold nanorod-phenothiazine dispersions}

To $1.5 \mathrm{~mL}$ of acetone an aliquot of the phenothiazine stock solution was added: $30 \mu \mathrm{L}$ (to give $c$ (phenothiazine) $=3.24 \mu \mathrm{M}$ ), $10 \mu \mathrm{L}$ (to give $c$ (phenothiazine) $=1.11 \mu \mathrm{M}$ ) or $1 \mu \mathrm{L}$ (to yield $c$ (phenothiazine) $=0.11 \mu \mathrm{M}$ ) of phenothiazine in the final solution. $1.0 \mathrm{~mL}$ of water was added to the solution, followed by $0.5 \mathrm{~mL}$ of gold nanorod dispersion and the combined solution was thoroughly mixed. $0.2 \mathrm{~mL}$ of the sample was placed into an NMR tube and the Raman spectrum was recorded immediately. Dispersions of spherical Au-NPs and Au-NRs with phenzothiazines had the same final concentration.

\section{Results and discussion}

The nanoparticle dispersions were synthesized in water with trisodium citrate for spherical nanoparticles and CTAB for $\mathrm{Au}-$ NRs as capping agents to obtain stable dispersions. We chose gold nanomaterials over other metal nanoparticles, because of their higher stability and reported potential in photocurrent enhancement. ${ }^{26,27}$ PD 1-6 were essentially insoluble in water, i.e. the solubility was below the detection limit of UV/Vis and Raman spectroscopy. For studying the interaction of PD 1-6 with gold nanoparticles in solution a solvent system had to be established. From their non-polar structure, the phenothiazine dyes exhibited good solubility only in nonpolar solvents such as dichloromethane. While their solubility in water-miscible solvents, such as acetonitrile and ethanol, was too poor, watermiscible acetone allowed for preparing phenothiazine dye solutions with a concentration up to $0.33 \mathrm{mM}$. Still, this concentration was not high enough for solution-state Raman spectroscopy. Therefore, comparisons of the PD@Au-NP solution spectra had to be made with solid-state Raman spectra of the neat phenothiazine dyes. Fig. 4 shows the solid state spectrum of PD 1. The strong signals around $1600 \mathrm{~cm}^{-1}$ refer to the "C $=\mathrm{C}$ " stretching vibrations. At $1225 \mathrm{~cm}^{-1}$ signals for $\mathrm{C}-\mathrm{H}$ stretching vibrations, and at $1407 \mathrm{~cm}^{-1}-\mathrm{CH}_{2}$ and $-\mathrm{CH}_{3}$ stretching vibrations are visible. At $2228 \mathrm{~cm}^{-1}$ signals for the $-\mathrm{C} \equiv \mathrm{N}$ group are seen. The signals for $-\mathrm{C}=\mathrm{O}$ in other phenothiazines were present at $1650-1800 \mathrm{~cm}^{-1}$, depending on the functional group present in the PD.

Very weak signals of $\mathrm{C}-\mathrm{C}$ vibrations appeared at 670 $1100 \mathrm{~cm}^{-1}$. Of special interest are $\mathrm{C}=\mathrm{C}$ stretching vibrations, which occur for all used phenothiazines as very strong signals (see Fig. S7 in ESI $\dagger)^{47}$

\section{Spherical gold nanoparticles (Au-NP)}

The plasmon resonance of spherical gold nanoparticles in water at $525 \mathrm{~nm}^{48}$ is slightly shifted to $528 \mathrm{~nm}$ upon addition of acetone (to a water/acetone $1: 1 \mathrm{v} / \mathrm{v}$ mixture). In addition, a shoulder formed at around $680 \mathrm{~nm}$ which grew in intensity
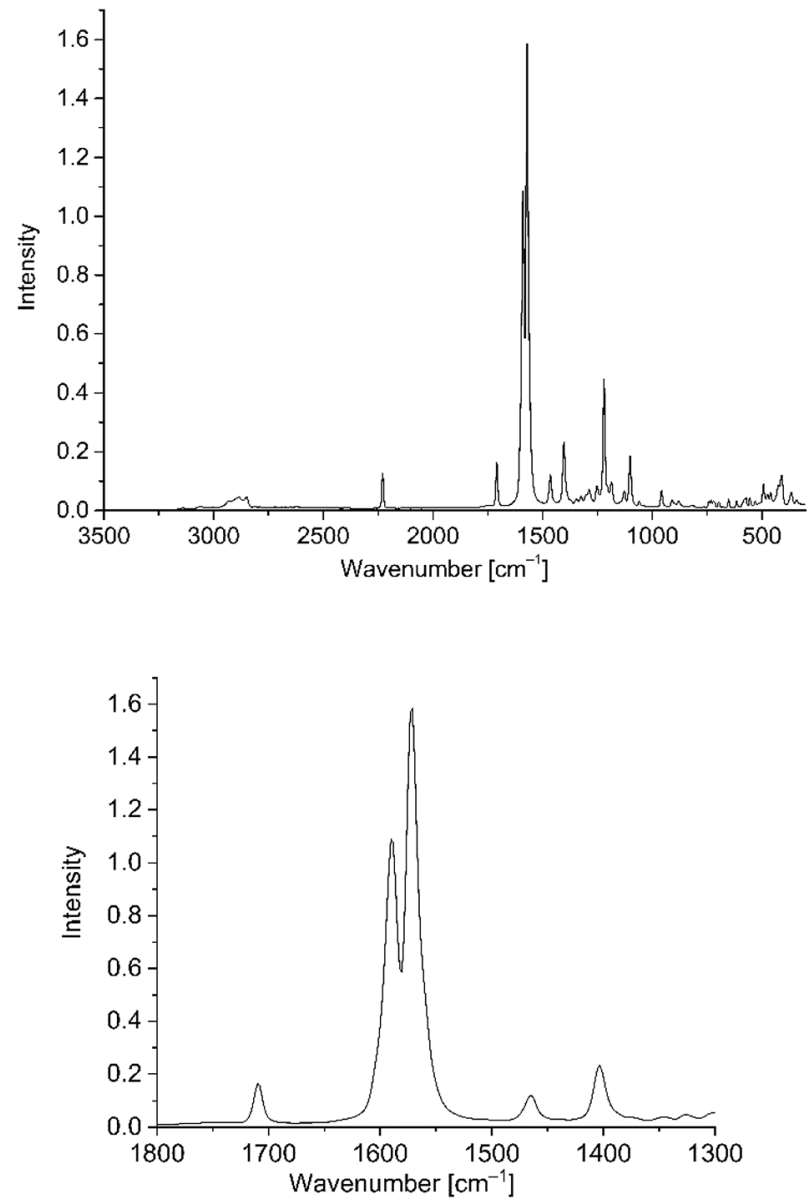

Fig. 4 Solid-state Raman spectrum of PD 1 (top) as overview from 3500 to $500 \mathrm{~cm}^{-1}$ and (bottom) with the relevant $\mathrm{C}=\mathrm{C}$ stretching region from 1800 to $1300 \mathrm{~cm}^{-1}$ which was used for the subsequent SERS studies. It is important, that the signal at $1600 \mathrm{~cm}^{-1}$ does not interfere with the solvent signals from the water/acetone mixture (Fig. S7 in ESI $\dagger$ ).

over the first 10 minutes and then remained stable for $17 \mathrm{~h}$ (Fig. 5). This suggests agglomeration of the Au-NPs after the addition of acetone.

The agglomeration of the Au-NPs in the $\mathrm{H}_{2} \mathrm{O}$ /acetone dispersion was not evident in TEM images in comparison to TEM images from the aqueous Au-NP dispersion (compare Fig. S1 and S4 in ESI $\dagger$ ) as the preparation of the TEM grids involved drying of the deposited dispersion, which will already have lead to some inherent aggregation.

Initial SERS studies on the PD@Au-NP mixtures showed no phenothiazine signals due to the difference between the Au-NP LSPR $(528 \mathrm{~nm})$ and the excitation wavelength of the nearinfrared (NIR) laser (1064 nm). We decided to only show Raman measurements after the induced agglomeration of the nanoparticles with $\mathrm{KCl}$, because of the higher SERS enhancements. Since the results were reproducible, we used this method with all phenothiazine dyes.

To excite the LSPR of the nanoparticles for obtaining the SERS effect, the laser excitation wavelength should be as close as possible to the LSPR. Instead of changing to a lower 


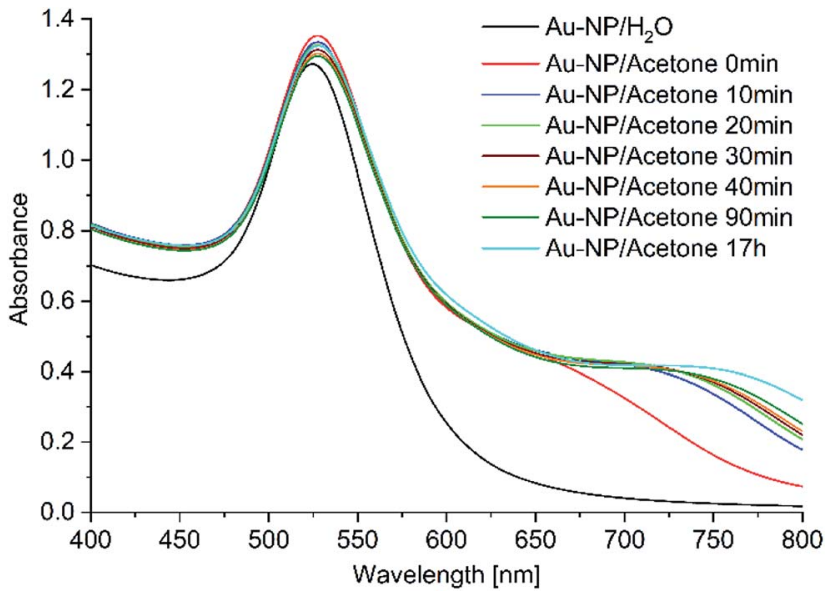

Fig. 5 Time-dependent UV/Vis study of aqueous Au-NP after the addition of acetone (to a $1: 1 \mathrm{v} / \mathrm{v}$ mixture).

excitation wavelength like $785 \mathrm{~nm}$ or below, we decided to stay at an excitation wavelength of $1064 \mathrm{~nm}$, because the phenothiazine dyes showed intense fluorescence in the range between $600-800 \mathrm{~nm}$. This could lead to strong fluorescence background scattering in the Raman spectra.

To adjust the plasmon resonance of gold nanoparticles towards the excitation wavelength of $1064 \mathrm{~nm}$ we induced $\mathrm{Au}-$ NP agglomeration with potassium chloride, which is well known for liquid state SERS measurements. ${ }^{44}$ The Au-NP/KCl dispersion was stable for at least $30 \mathrm{~min}$, underwent precipitation after $45 \mathrm{~min}$ and the plasmon resonance shifted to higher wavelengths. After the addition of $10 \mathrm{mg} \mathrm{KCl}$ to $3 \mathrm{~mL}$ of the Au-NP water-acetone mixture the LSPR at $528 \mathrm{~nm}$ shifted to a broad band around $800 \mathrm{~nm}$ (Fig. 6), but at over $1000 \mathrm{~nm}$ there is still a significant absorption due to the LSPR of the spherical particles. To verify the absorption of the Au-NPs in the near-infrared, additional absorption spectra were measured (Fig. S3 bottom in ESI $\dagger$ ). The NIR spectrum still shows an absorption at $1064 \mathrm{~nm}$, indicating that the Au-NPs are useable for SERS excitation. The peak for the LSPR of remaining non-aggregated spherical particles decreased in intensity and shifted slightly from 528 to $535 \mathrm{~nm}$. The TEM image shows significant agglomeration (compare to Fig. S1 or S4 in ESI $\dagger$ ). The primary particles retained their spherical morphology and did not change their size (average diameter $36 \pm 7 \mathrm{~nm}$ ). In the agglomerates small holes and gaps are apparent with a width between $2 \mathrm{~nm}$ and $14 \mathrm{~nm}$. These gap sizes match with the sizes for previously reported "hot spots" in SERS measurements. ${ }^{40}$

Nanoparticle agglomeration can be used to adjust the plasmon resonance of nanoparticles, and was applied in SERS measurements before. ${ }^{49}$

\section{SERS results with spherical gold nanoparticles (Au-NP)}

Phenothiazine dyes 1 and 2. Both PD 1 and 2 showed intense Raman signals at around 1561 and $1590 \mathrm{~cm}^{-1}$ in the presence of $\mathrm{Au}-\mathrm{NPs} / \mathrm{KCl}$ (Fig. 7 and S8 in ESI $\dagger$ for PD 2). These Raman signals could be assigned to the $\mathrm{C}=\mathrm{C}$ stretching vibrations ( $c f$.
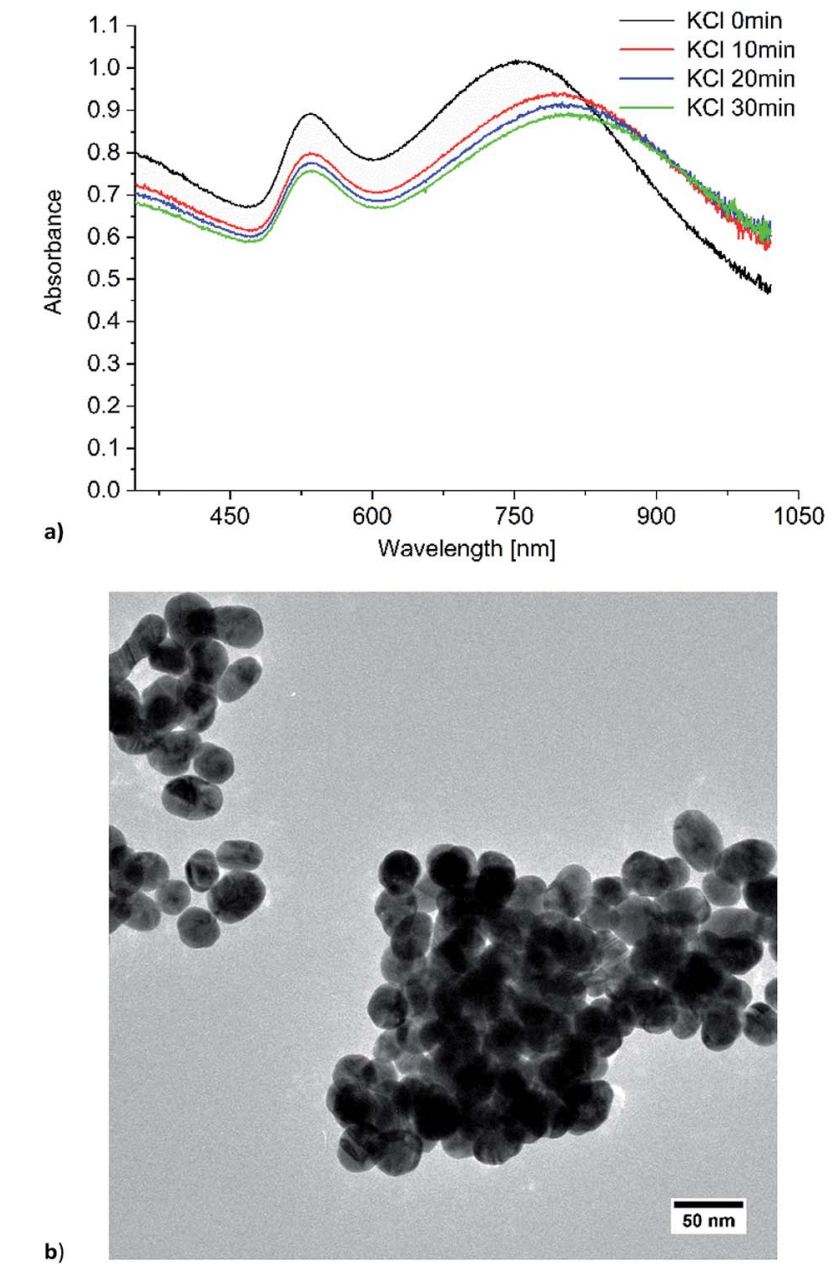

Fig. 6 (a) Time dependent UV/Vis absorption and (b) TEM image of $\mathrm{Au}-\mathrm{NPs}$ in water/acetone $(1: 1 \mathrm{v} / \mathrm{v})$ with $\mathrm{KCl}$ added.

Fig. 4). In the absence of Au-NPs no dye related Raman signals were seen at the concentrations of $3.24,1.11$ and $0.11 \mu \mathrm{M}$. To excite Raman signals at around $1500 \mathrm{~cm}^{-1}$ with a $1064 \mathrm{~nm}$ laser, the Au-NPs need to have an absorption at around $1260 \mathrm{~nm}$,

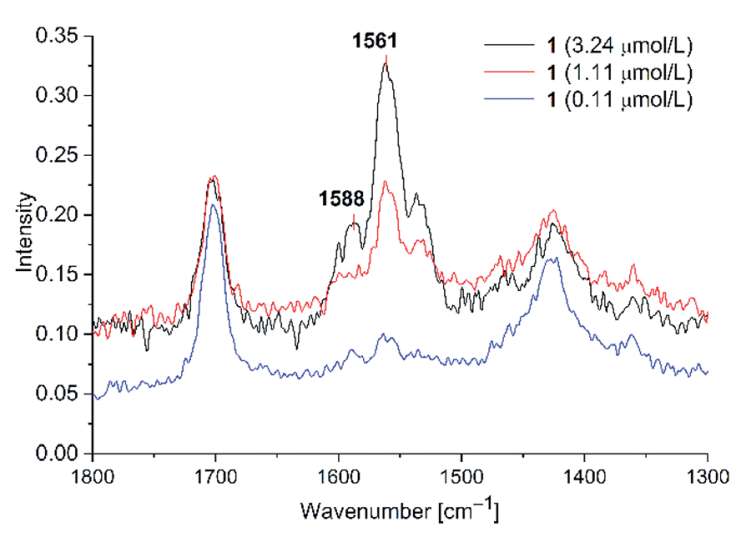

Fig. 7 SERS studies (200 mW) for PD 1@Au-NP at concentrations of 3.24, 1.11 and $0.11 \mu \mathrm{M}$ in $\mathrm{H}_{2} \mathrm{O} /$ acetone $(1: 1 \mathrm{v} / \mathrm{v})$ and $\mathrm{KCl}$ added (see Fig. $\mathrm{S} 8$ in ESI† for PD 2). 
which was achieved for the KCl-agglomerated Au-NPs ( $c f$. Fig. S3, bottom in ESI $\dagger$ ). For PD 1 at the concentration of 1.11 $\mu \mathrm{M}$ the $\mathrm{C}=\mathrm{C}$ vibration at $1588 \mathrm{~cm}^{-1}$ appears only as a shoulder, while it is a small peak for PD 2 ( $c f$ Fig. S8 in ESI $\dagger$ ). We think that this is caused by variations of the signal intensities for liquid state Raman spectroscopy due to the Brownian motion of molecules in the laser beam. For PD 1 and 2 the limit of detection (LOD) was reached at a concentration of $0.11 \mu \mathrm{M}$. Both rhodanine based dyes show strong SERS signals with spherical gold nanoparticles, leading to a very low LOD of 0.11 $\mu \mathrm{M}$, which can be correlated to the known affinity and bond formation between gold and sulfur ${ }^{50}$ of the $S$-thiocarbamate functionality of the rhodanine group. For PD 2 the SERS enhancement was slightly smaller than for PD 1, so enhancement of the laser power to $700 \mathrm{~mW}$ was needed for clear identification of Raman signals at $0.11 \mu \mathrm{M}$. Since it would be possible to see SERS enhancements for all three concentrations at a laser power of $700 \mathrm{~mW}$, we decided, that $0.11 \mu \mathrm{M}$ can be taken as the LOD. At lower concentrations we were not able to identify any PD related Raman signals at laser intensities up to $1000 \mathrm{~mW}$.

The signal to noise ratio appears to be low for the measured SERS spectra, which is caused by several reasons. We only show sections of the whole Raman spectra to depict the interesting signals of the spectra. The dye signals in the presented spectra are much smaller than the solvent signals because of their low concentrations. In this time-dependent measurement we were limited by the stability of the nanoparticle dispersions. In all SERS spectra the identified SERS signals are clearly stronger than the background noise. Also, we can note, that in Raman spectroscopy the intensity of Raman signals decreases with higher excitation wavelength, leading to lower $\mathrm{S} / \mathrm{N}$ ratios.

Phenothiazines 3 and 4 . PD 3 and 4 with the 1,3-indanedione functionality could be detected at concentrations of 3.24 and $1.11 \mu \mathrm{M}$ (Fig. 8 and S10 for compound 4 in ESI $\dagger$ ) with an enhanced laser power of 500 to $700 \mathrm{~mW}$, which was necessary because of a lower SERS enhancement compared to PD 1,2.

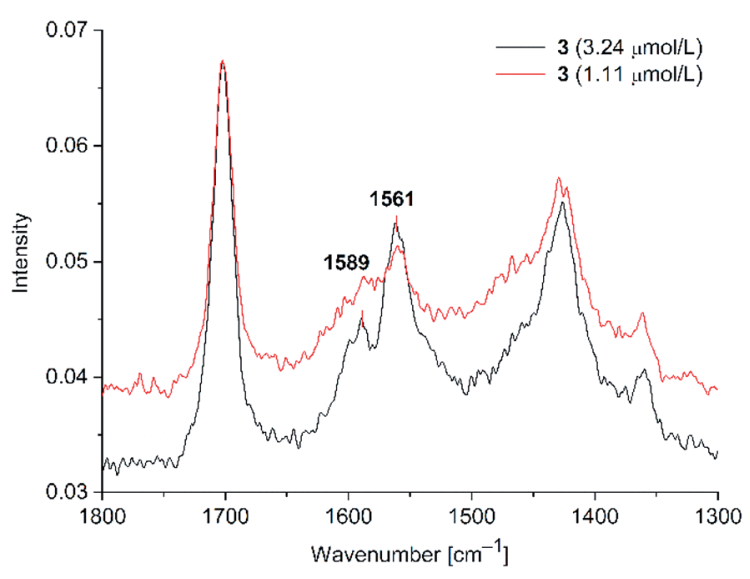

Fig. 8 SERS studies for PD 3@Au-NP at $3.24 \mu \mathrm{M}(500 \mathrm{~mW})$ and $1.11 \mu \mathrm{M}$ (700 $\mathrm{mW}$ ) in $\mathrm{H}_{2} \mathrm{O} /$ acetone $(1: 1 \mathrm{v} / \mathrm{v}$ ) with $\mathrm{KCl}$ added. (see $\mathrm{S} 10$ in $\mathrm{ESI} \dagger$ for PD 4).
Peak positions are matching with the solid state $\mathrm{C}=\mathrm{C}$ signals. For both dyes 3 and $\mathbf{4}$ we observed the SERS effect, albeit only at a higher laser power in comparison to PD 1 and 2. Also, the signal enhancement was smaller than for the rhodanine dyes 1 and 2. The detection limit was $1.11 \mu \mathrm{M}$ for PD 3 and $\mathbf{4}$, indicating a weaker interaction of $\mathbf{3}$ and $\mathbf{4}$, which lack a sulfur donor group, with the gold nanoparticles. At this concentration, only the stronger $\mathrm{C}=\mathrm{C}$ vibration at $1561 \mathrm{~cm}^{-1}$ appears as a clearly discernible Raman signal, while the $\mathrm{C}=\mathrm{C}$ vibration at $1589 \mathrm{~cm}^{-1}$ is only visible as a small shoulder.

Phenothiazines 5 and 6. PD 5 and 6 containing a cyanoacrylic acid group could not be detected at concentrations below $3.24 \mu \mathrm{M}$ (Fig. 9, and S11 for PD 6 in ESI†) and a laser intensity of $500 \mathrm{~mW}$.

Even at a concentration of $3.24 \mu \mathrm{M}$ only very small signal intensities were observed at wavenumbers matching with the solid state spectra of PD 5. In addition to the Raman spectra fluorescence spectra for all phenothiazines were measured upon the addition of water and gold nanoparticle dispersion. PD 1-4 showed fluorescence quenching after addition of water and nanoparticles (see Fig S12, S13, S15 and S16 in ESI†). The emission spectra for phenothiazines $\mathbf{5}$ and $\mathbf{6}$ showed a different behaviour (Fig. 10).

The addition of an aqueous nanoparticle dispersion caused a hypsochromic shift in the emission spectrum of 5 from $608 \mathrm{~nm}$ to $535 \mathrm{~nm}$ with an isosbestic point at $601 \mathrm{~nm}$ upon increasing the amount of nanoparticle dispersion (Fig. 10; see Fig. S14 in ESI $\dagger$ for the fluorescence spectra of 6). We assume the formation of $\mathrm{H}$-aggregates as the origin of the hypsochromic shift and the fluorescence attenuation. ${ }^{51} \mathrm{H}$ aggregates can be plausibly rationalized by replacement of the head-to-tail hydrogen bonding of the carboxylic acid group in acetone by hydrogen bonding to water with the increasing addition of aqueous Au-NP dispersion..$^{52}$ Comparable studies with stepwise addition of water showed a similar hypsochromic shift due to the formation of $\mathrm{H}$-aggregates in the fluorescence spectrum from $608 \mathrm{~nm}$ to $550 \mathrm{~nm}$ without an isobestic point for 5 (see Fig. S17 for 5 and Fig. S18 for $6 \dagger$ ). This

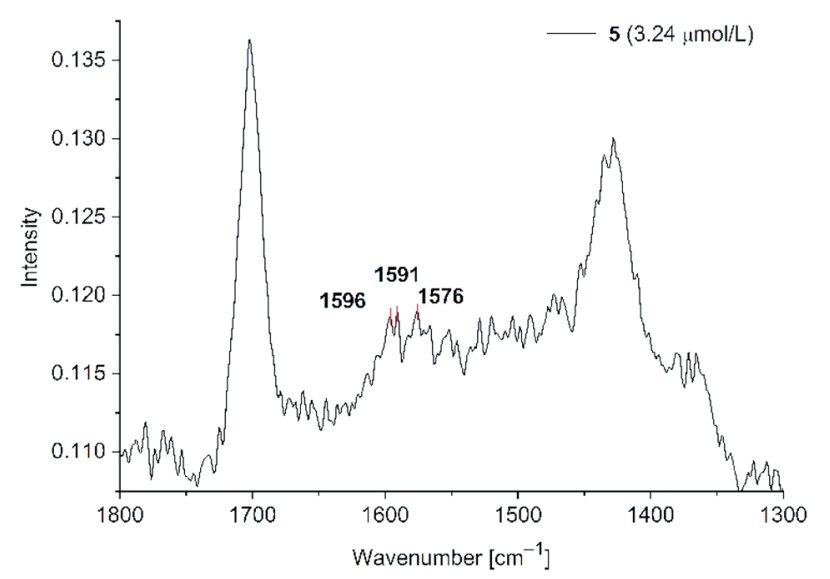

Fig. 9 SERS studies for PD 5(Au-NP at $3.24 \mu \mathrm{M}(500 \mathrm{~mW})$ in $\mathrm{H}_{2} \mathrm{O}$ / acetone $(1: 1 \mathrm{v} / \mathrm{v})$ in the presence of $\mathrm{KCl}$ (see Fig. S11 in ESI† for PD 6). 


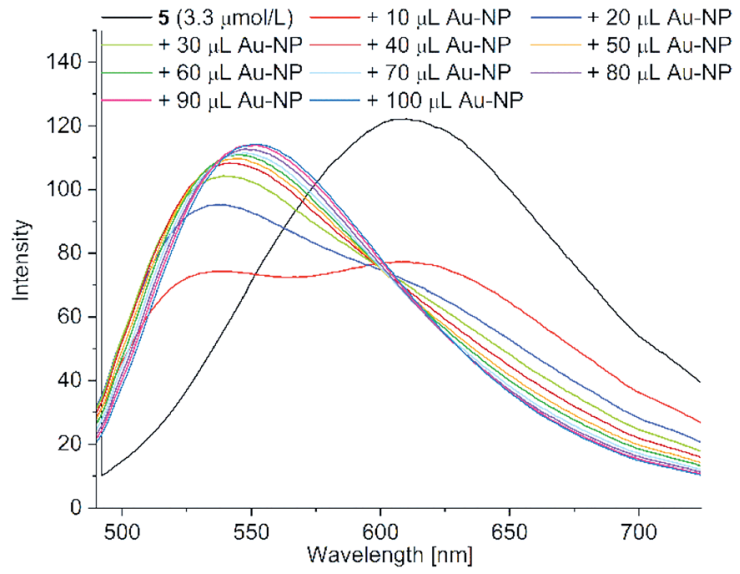

Fig. 10 Fluorescence spectra of acetone solutions of PD $5(c=3.3 \mu \mathrm{M})$ with the stepwise addition of $10 \mu \mathrm{L}$ aliquots of the aqueous Au-NP dispersion up to a total of $100 \mu \mathrm{L}$ (excitation wavelength $=428 \mathrm{~nm}$ ) (see Fig. S14 in ESI† for the fluorescence spectra of PD 6).

hydration of the carboxyl group presumably also prevents the cyanoacrylic carboxyl coordination to the gold nanoparticles, which has to occur in competition to the present citrate capping ligand. Consequently, this leads to much smaller SERS enhancements for PD 5 and 6.

We observed no effects due to the used trisodium citrate in our SERS spectra. There are numerous publications, which use trisodium citrate as a reducing and stabilizing agent in the synthesis of plasmonic particles for SERS experiments. In principle, it should be possible to detect the surfactant via SERS enhancement, but we assume that the interactions between the phenothiazine dyes and the Au-NP are stronger than the weak electrostatic interactions between trisodium citrate and gold. It is known that the citrate surfactant can be replaced easily by stronger bound surfactants with e.g. thiol groups. ${ }^{50} \mathrm{We}$ also noticed no effects or signals on the SERS studies, which we correlated with trisodium citrate.

Gold nanorods. In addition to spherical gold nanoparticles, gold nanorods (Au-NRs) were also prepared for SERS experiments, because the LSPR of Au-NRs is tuneable through their length and their aspect ratio value. ${ }^{46,53,54}$ Therefore, the nanorod dispersion did not require induced agglomeration (by $\mathrm{KCl}$ addition) to approach the excitation wavelength of $1064 \mathrm{~nm}$. Thus, the nanorods did not precipitate, but formed a stable dispersion throughout the measurements. Gold nanorods were synthesized using a seedless synthesis ${ }^{53}$ with dopamine as reducing agent. We synthesised gold nanorods with a size distribution of $89 \pm 13 \mathrm{~nm}$ for the nanorod length and $21 \pm$ $6 \mathrm{~nm}$ for the nanorod width as analyzed by TEM and UV/Vis spectroscopy (see Fig. S5 and S6 in ESI $\dagger$ ). There are three broad absorption bands for the LSPR in the UV/Vis spectrum of Au-NRs. The band at $542 \mathrm{~nm}$ originates from the transverse axis (or thickness) and the band at $937 \mathrm{~nm}$ a peak from the longitudinal axis. At $779 \mathrm{~nm}$ we detected a small peak for gold nanoprisms (see Fig. S5 in ESI $\dagger$ ), where the reaction was not completed to nanorods. At 600-700 nm there were sharp bands in the spectrum, which were reproducible and may have been caused by the surfactant CTAB or impurities from the synthesis. These signals can also be found in the literature for seedless synthesis methods, but were not explained. ${ }^{53 a}$

For the Au-NRs in an acetone/water mixture (1:1), the band at $540 \mathrm{~nm}$ did not change its position, while the band at $778 \mathrm{~nm}$ shifted to $693 \mathrm{~nm}$ and the one $936 \mathrm{~nm}$ to $978 \mathrm{~nm}$ (see Fig. S19 in ESI $\dagger$ ). The shifts of the latter two bands could be explained by agglomeration of the nanorods. Addition of $\mathrm{KCl}$ led only to rapid precipitation of the nanorods and was not investigated further.

Initial SERS experiments with Au-NRs led to no SERS enhancement, because the high amounts of the structure forming and stabilizing agent $\mathrm{CTAB}$ on the NR surface interfered with SERS measurements. The surfactant CTAB is strongly bound to the metal surface, competing with the phenothiazine analytes for binding sites. ${ }^{55}$ CTAB stabilizes the Au-NR by formation of a bilayer. In the growth phase of the nanorods positively charged CTAB headgroups interact with the metal surface. In the second layer the headgroups orient themselves towards the solvent. This leads to a hydrophobic plenum between the layers comparable to a cellular membrane. ${ }^{56}$ Reduction of the amount of CTAB during the AuNR synthesis was not possible, because the surfactant is indispensable for the formation of Au-NRs. CTAB forms micelles where nanorods are grown..$^{55}$ Their length correspond to the CTAB concentration. ${ }^{53,53 a}$ Removing the CTAB with $\mathrm{HCl}$ by a protocol published by Cui et al. ${ }^{57}$ was successful, but led to fast Au-NR agglomeration and precipitation, which made it impossible to record Raman spectra. Instead, excessive CTAB was removed via centrifugation. The nanorod dispersion was centrifuged, washed and redispersed two times for 15 minutes at 8000 RPM and then redispersed in ultrapure water to decrease the amount of CTAB in the dispersion.

\section{SERS results with gold nanorods (Au-NR)}

Phenothiazines 1 and 2. When the rhodanine functionalized PD 1 and 2 were exposed to gold nanorods, the signals at 1565

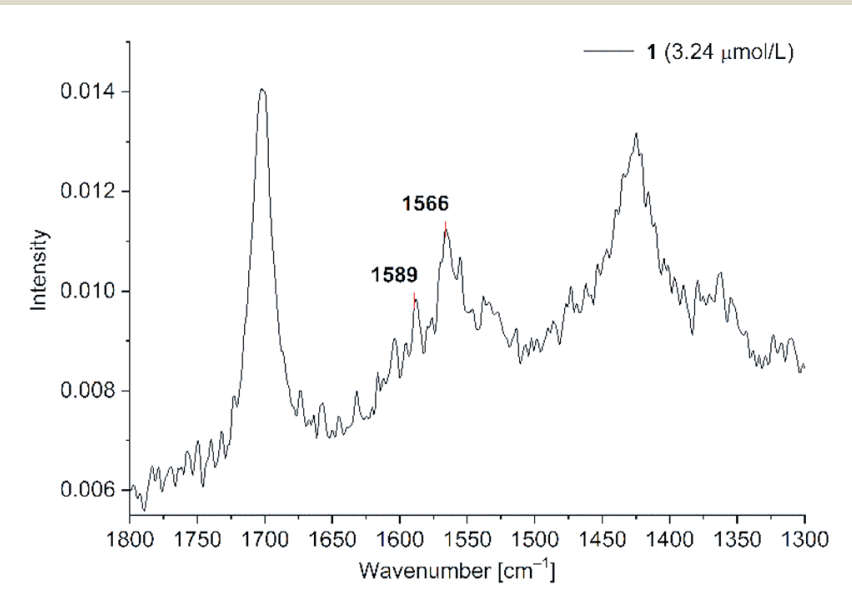

Fig. 11 SERS studies (200 mW) for PD 1@Au-NR at $3.24 \mu \mathrm{M}$ in $\mathrm{H}_{2} \mathrm{O}$ / acetone $(1: 1 \mathrm{v} / \mathrm{v})$. See Fig. S20 for PD 2 in ESI. $\dagger$ 
and $1588 \mathrm{~cm}^{-1}$ indicated a SERS enhancement (Fig. 11, for PD 2 see Fig. S20 in ESI†).

Signal intensities were not as high as for agglomerated spherical nanoparticles, but the Au-NR dispersions were stable for over $2 \mathrm{~h}$ instead of $45 \mathrm{~min}$. The signal intensity was lower because no hot-spots between the nanorods were formed. Furthermore, the remaining $\mathrm{CTAB}$ capping ligands are reducing the signal intensity through blocking binding sites at the nanorods. A brief test after the removal of CTAB showed more intense SERS signals, but with highly destabilized dispersions. When the concentration of 1 was lowered to $1.11 \mu \mathrm{M}$ after the removal of excess CTAB (Fig. 12, for compound 2 see ESI Fig. S21 $\dagger$ ) the two characteristic phenothiazine signals at 1563 and $1586 \mathrm{~cm}^{-1}$ were still clearly visible. CTAB shows no Raman signals in the range of $1500-1600 \mathrm{~cm}^{-1}$. For CTAB there should be Raman signals at around $1400 \mathrm{~cm}^{-1}$ which, however, overlap with the solvent signals, which are far more intensive. The overall signal background increased in all CTAB stabilized samples compared to the spherical nanoparticles. Such an increased background is sometimes seen in the literature for gold nanorods without explanation. ${ }^{58}$ We believe that the background noise in the Au-NR measurements is due to the cationic surfactant and not by fluorescence excitation. It was not possible to detect SERS enhancements of $\mathbf{1}$ and $\mathbf{2}$ at concentrations lower than $1.11 \mu \mathrm{M}$.

Phenothiazines 3 and 4. The 1,3-indanedione based phenothiazine dyes showed barely visible SERS enhancements at 3.24 $\mu \mathrm{M}$ (PD 3 in Fig. 13 and PD 4 see ESI S22 $\dagger$ ).

Phenothiazines 5 and 6. For those phenothiazine derivatives, containing a cyanoacrylic acid group, we were not able to detect SERS enhancements even at high laser intensities of $700 \mathrm{~mW}$ (as an example see PD 6 in Fig. S23 in the ESI†). Alternatively, fluorescence spectra show a shift in the signal for PD 5 after the addition of $100 \mu \mathrm{L}$ nanorod dispersion (Fig. 14, see Fig. S26† for PD 6).

After the addition of nanorods, the hypsochromic signal shift is not as pronounced as after the addition of spherical gold nanoparticles ( $c f$. Fig. 9). Again, this shift could be due to the $\mathrm{H}$ -

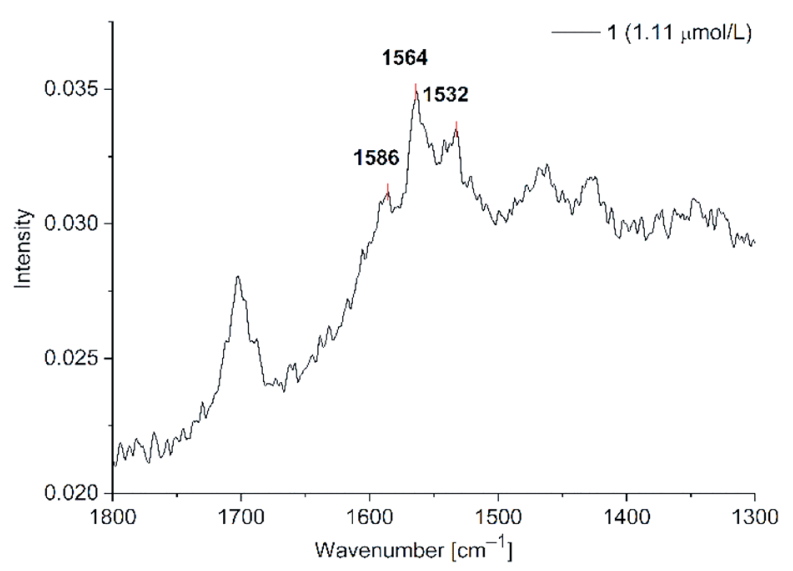

Fig. 12 SERS studies (200 mW) for PD 1@Au-NR at $1.11 \mu \mathrm{M}$ in $\mathrm{H}_{2} \mathrm{O}$ / acetone $(1: 1 \mathrm{v} / \mathrm{v})$ (section between $\left.1800-1300 \mathrm{~cm}^{-1}\right)$. See Fig. S21 for PD 2 in ESI. $\dagger$

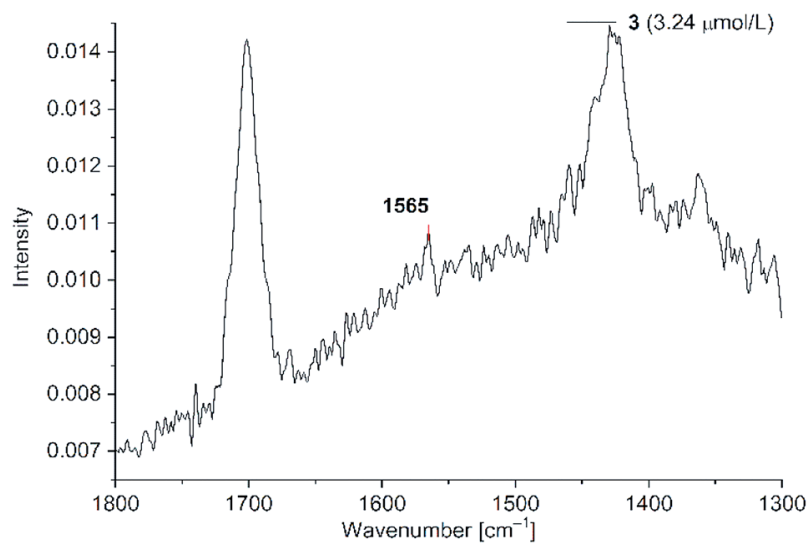

Fig. 13 SERS studies (200 mW) for PD 3@Au-NR at $3.24 \mu \mathrm{M}$ in $\mathrm{H}_{2} \mathrm{O}$ / acetone $\left(1: 1 \mathrm{v} / \mathrm{v}\right.$ ) (section between $1800-1300 \mathrm{~cm}^{-1}$ ). See Fig. S22 for PD 4 in ESI. $\dagger$

aggregate formation of hydrogen bonds between carboxylic acid and water or carboxylic acid with itself. The effect is not as strong as seen with the spherical particles. We assume that the presence of CTAB, a cationic tenside, in the dispersion hampers the formation of hydrogen bonds as a consequence of its surfactant function. CTAB on the surface of the nanorods forms a bilayer with a hydrophobic plenum, which expels the hydrophilic carboxylic acid leading to no SERS enhancement. We also assume that the hydrophilic groups of the surfactant interact with water and the carboxylic acids of $\mathbf{5}$ and $\mathbf{6}$, minimizing the formation of $\mathrm{H}$-aggregates.

We were able to measure the LODs of all dyes with Au-NPs and PD 1-4 with Au-NR (Table 1).

Since all six phenothiazine dyes are novel it is not possible to compare the detection sensitivity to other reported studies. Compared to SERS measurements of other phenothiazine dyes like methylene blue, there are reports with comparable LODs. Trindade et al. measured concentrations of $10^{-4} \mathrm{M}$ of dye adsorbed in fibers. ${ }^{59} \mathrm{Jang}$ et al. measured methylene blue

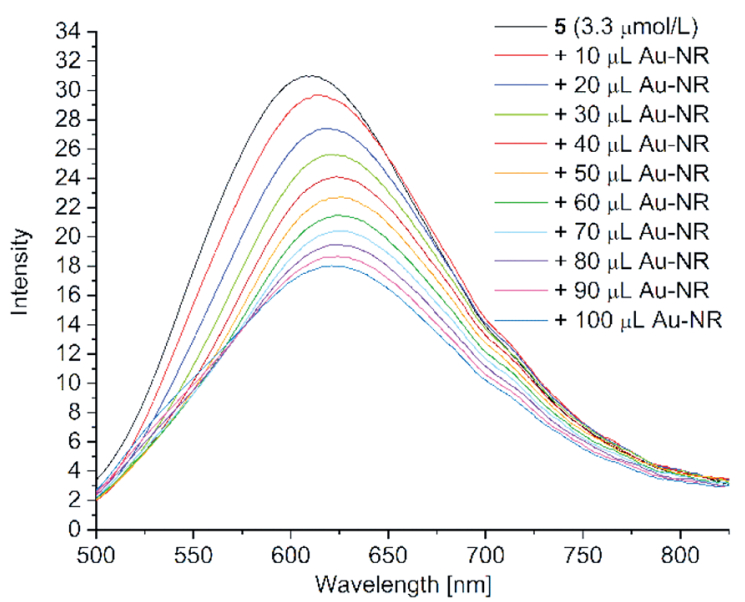

Fig. 14 Fluorescence spectra of PD $5(c=3.3 \mu \mathrm{M})$ with the stepwise addition of $100 \mu \mathrm{L}$ Au-NR (excitation wavelength $=428 \mathrm{~nm}$ ). 
Table 1 Comparison of the measured LODs of PD 1-6 with Au-NP and $\mathrm{Au}-\mathrm{NR}$

\begin{tabular}{lll}
\hline PD & LOD $[\mu \mathrm{M}]$ Au-NP & LOD $[\mu \mathrm{M}] \mathrm{Au}-\mathrm{NR}$ \\
\hline $\mathbf{1}$ & 0.11 & 1.11 \\
$\mathbf{2}$ & 0.11 & 1.11 \\
$\mathbf{3}$ & 1.11 & 3.24 \\
$\mathbf{4}$ & 1.11 & 3.24 \\
$\mathbf{5}$ & 3.24 & - \\
$\mathbf{6}$ & 3.24 & -
\end{tabular}

with Au-NRs surrounded by a $\mathrm{SiO}_{2}$ shell with an LOD of 10.4 $\mu \mathrm{M}$ and $3.6 \mu \mathrm{M} .{ }^{60}$ Camacho-López et al. were able to measure methylene blue using a Raman microscope at concentrations of $10^{-10} \mathrm{M}$ on $\mathrm{Au} / \mathrm{Ag}$ nanoparticles after evaporation of a dye solution for depositing and fixing the dye on the particle surface. ${ }^{61}$ These works show the wide range of LODs for dyes depending on the used plasmonic material and the measuring method. In our experiments we measured the dyes in the solution state as an easy and fast way to prepare SERS samples.

\section{Conclusions}

We were able to obtain SERS spectra with all six phenothiazine dyes after the addition of citrate-stabilized spherical gold nanoparticles, albeit only after the $\mathrm{KCl}$-induced formation of hot spots, thereby providing evidence of interactions between gold nanoparticles and the phenothiazine dyes. Differences in SERS signal enhancement vary with the different functional groups of the dyes. PD 1 and 2 showed the lowest level of detection indicating strong interactions with the gold nanoparticles. We assume the formation of $\mathrm{Au}-$ $S$ bonds lead to these intense contacts of nanoparticles and dyes. 1,3-indanedione containing PD 3 and 4 showed lower SERS intensities than the sulphur-containing PD 1,2. This indicates a weaker contact with the gold nanoparticles through adsorption, lacking the sustained contact to the nanoparticles through a chemical bond like for the rhodanine group. For the cyanoacrylic acid containing PD 5,6 only weak enhancements in the SERS spectra at a LOD of 3.24 $\mu \mathrm{mol} \mathrm{L}{ }^{-1}$ were apparent, leading to the conclusion that these dyes could not bond or adsorb to the surface of the gold nanoparticles.

In addition to SERS studies, fluorescence studies were conducted to determine the utility of gold nanoparticles for use in Grätzel type solar cells. For rhodanine and 1,3-indanedione based phenothiazines 1-4, fluorescence attenuation was not observed after the addition of the aqueous nanoparticle dispersion in comparison to the addition of water alone which led to fluorescence quenching. We assume that these dyes interact with the LSPR of the gold nanoparticles and show no enhanced fluorescence quenching through the gold nanoparticles and nanorods. For these dyes, an enhancement of photocurrents by the addition of gold nanoparticles can be possible.
For 5 and 6 only weak enhancements in the SERS spectra were apparent. At the same time a strong hypsochromic shift by $\sim 70 \mathrm{~nm}$ is seen in fluorescence spectra. We assume that this is caused by the formation of $\mathrm{H}$-aggregates in the presence of water. Since citrate stabilized gold nanoparticles are not very stable in organic solvents, we were not able to carry out studies without the addition of water. We conclude, that the possible formation of $\mathrm{H}$-aggregate inhibits the use of these dyes in dye-sensitive solar cells.

For CTAB-stabilized gold nanorods, we were also able to record SERS spectra for PD 1-4. The detection limits were not as low as for the spherical gold particles due to the necessary presence and resulting surface-shielding effect of CTAB and missing SERS hot spots. Thus, SERS enhancements with gold nanorods were weaker than with gold nanoparticles and showed less hypsochromic shifts in the fluorescence spectra. One advantage of gold nanorods is the control of the LSPR through size control during the synthesis.

The order of SERS intensity for the PDs was rhodanine PD 1,2 $>$ 1,3-indanedione PD 3,4 $>$ cyanoacrylic acid PD 5,6. This order was the same with the gold nanoparticles and the gold nanorods. Overall, gold nanostructures could be suitable for enhancing photocurrents of the presented phenothiazine dyes in Grätzel type solar cells. In particular, easier to synthesize spherical nanoparticles allow for stronger interactions due to formation of "hot spots" and the absence of the strongly-bound surfactant CTAB.

We conclude that phenothiazine-merocyanine dyes 1-4 show potential for the usage in Grätzel type DSSCs with incorporated gold nanostructures. The spherical nanoparticles induced no enhanced fluorescence quenching and showed strong SERS signals depending on the interactions with the functional groups. Since SERS and photocurrent enhancement both use the nanoantennae effect of the LSPR, we can assume, that the dyes PD 1-4 should show photocurrent enhancement in the presence of gold nanostructures in DSSCs. Spherical nanoparticles are favoured against gold nanorods because of their easy and fast synthesis and their ability to produce hot spot regions due to induced agglomeration. PD 5,6 showed great sensitivity against the presence of even small amounts of water, leading to drastic decreases in fluorescence intensity and prevention of interactions with plasmonic nanoparticles and therefore should not be considered for further use in photocurrent enhanced DSSCs.

\section{Conflicts of interest}

There are no conflicts to declare.

\section{Acknowledgements}

We thank Dr J. Barthel and the Ernst Ruska-Centrum für Mikroskopie und Spektroskopie mit Elektronen, 52425 Jülich (Germany) for the possibility to measure TEM images. 


\section{References}

1 R. A. Aitken and K. M. Aitken, 1,4-Thiazines and their Benzo Derivatives, Comprehensive Heterocyclic Chemistry III, 2008, vol. 8, ch. 8.09, pp. 607-675.

2 S. P. Massie, Chem. Rev., 1954, 54, 797-833.

3 J. F. Casey, J. J. Lasky, C. J. Klett and L. E. Hollister, Am. J. Psychiatry, 1960, 117, 97-105.

4 S. H. Snyder, S. P. Banerjee, H. I. Yamamura and D. Greenberg, Science, 1974, 184, 1243-1253.

5 M. J. Ohlow and B. Moosmann, Drug Discovery Today, 2011, 16, 119-131.

6 K. Hochgräfe, A. Sydow, D. Matenia, D. Cadinu, S. Könen, O. Petrova, M. Pickhardt, P. Goll, F. Morellini, E. Mandelkow and E.-M. Mandelkow, Acta Neuropathol. Commun., 2015, 3(25), 1-22.

7 (a) F. L. Campbell, W. N. Sullivan, L. E. Smith and H. L. Haller, J. Econ. Entomol., 1934, 27, 1176-1185; (b) N. F. Howard, L. W. Brannon and H. C. Mason, J. Econ. Entomol., 1935, 28, 444-448.

8 F. Deeds, A. B. Stockton and J. O. Thomas, J. Pharmacol. Exp. Ther., 1939, 65, 353-371.

9 (a) M. Hauck, M. Stolte, J. Schönhaber, H. G. Kuball and T. J. J. Müller, Chem. - Eur. J., 2011, 17, 9984-9998; (b) C. S. Krämer, K. Zeitler and T. J. J. Müller, Tetrahedron Lett., 2001, 42, 8619-8624; (c) D. Urselmann, B. Mayer and T. J. J. Müller, Beilstein J. Org. Chem., 2016, 12, 2055-2064; (d) M. Sailer, A. W. Franz and T. J. J. Müller, Chem. - Eur. J., 2008, 14, 2602-2614; (e) M. Sailer, M. Nonnenmacher, T. Oeser and T. J. J. Müller, Eur. J. Org. Chem., 2006, 2, 423-435.

10 (a) A. P. Kulkarni, P.-T. Wu, T. W. Kwon and S. A. Jenekhe, J. Phys. Chem. B, 2005, 109, 19584-19594; (b) T. Meyer, D. Ogermann, A. Pankrath, K. Kleinermanns and T. J. J. Müller, J. Org. Chem., 2012, 77, 3704-3715.

11 (a) N. Bucci and T. J. J. Müller, Tetrahedron Lett., 2006, 47, 8323-8327; (b) N. Bucci and T. J. J. Müller, Tetrahedron Lett., 2006, 47, 8329-8332; (c) S. Bay, T. Villnow, G. Ryseck, V. Rai-Constapel, P. Gilch and T. J. J. Müller, ChemPlusChem, 2013, 78, 137-141.

12 (a) T. J. J. Müller, Tetrahedron Lett., 1999, 40, 6563-6566; (b) C. S. Krämer and T. J. J. Müller, Eur. J. Org. Chem., 2003, 18, 3534-3548.

13 (a) C. S. Barkschat, S. Stoycheva, M. Himmelhaus and

T. J. J. Müller, Chem. Mater., 2010, 22, 52-63; (b)

A. W. Franz, S. Stoycheva, M. Himmelhaus and

T. J. J. Müller, Beilstein J. Org. Chem., 2010, 6, 72.

14 J. Rechmann, A. Sarfraz, A. C. Götzinger, E. Dirksen,

T. J. J. Müller and A. Erbe, Langmuir, 2015, 31, 7306-7316.

15 C. Buhrmester, L. Moshurchak, R. L. Wang and J. R. Dahn, J.

Electrochem. Soc., 2006, 153, A288-A294.

16 M. Notarianni, K. Vernon, A. Chou, M. Aljada, J. Liu and

N. Motta, Sol. Energy, 2014, 106, 23-37.

17 B. O ` Reagan and M. Grätzel, Nature, 1991, 353, 737-739.

18 M. Grätzel, J. Photochem. Photobiol., C, 2003, 4, 145-153.
19 J. Gong, J. Liang and K. Sumathy, Renewable Sustainable Energy Rev., 2012, 16, 5848-5860.

20 M. K. Nazeeruddin, A. Kay, I. Rodicio, R. Humphry-Baker, E. Müller, P. Liska, N. Vlachopoulos and M. Grätzel, J. Am. Chem. Soc., 1993, 115, 6382-6390.

21 S. Shalini, R. Balasundaraprabhu, T. Satish Kumar, N. Prabavathy, S. Senthilarasu and S. Prasanna, Int. J. Energy Res., 2016, 40, 1303-1320.

22 (a) A. S. Hart, K. C. Chandra Bikram, N. K. Subbaiyan, P. A. Karr and F. D'Souza, ACS Appl. Mater. Interfaces, 2012, 4, 5813-5820; (b) Z.-S. Huang, H. Meier and D. Cao, J. Mater. Chem. C, 2016, 4, 2404-2426.

23 A. Hagfeldt, G. Boschloo, L. Sun, L. Kloo and H. Pettersson, Chem. Rev., 2010, 110, 6595-6663.

24 (a) M. D. Brown, T. Suteewong, R. Sai Santosh Kumar, V. D'Innocenzo, A. Petrozza, M. M. Lee, U. Wiesner and H. J. Snaith, Nano Lett., 2011, 11, 438-445; (b) D. H. Song, H.-Y. Kim, H.-S. Kim, J. Sang Suh, B.-H. Jun and W.-Y. Rho, Chem. Phys. Lett., 2017, 687, 152-157.

25 (a) B. Törngren, S. Sandén, J. O. Nyman, A. Tiihonen, H. Jiang, J. Ruokolainen, J. Halme, R. Österbacka and J.-H. Smått, J. Nanopart. Res., 2017, 19, 365-376; (b) S. Chang, Q. Li, X. Xiao, K. Y. Wong and T. Chao, Energy Environ. Sci., 2012, 5, 9444-9448.

26 T. Kawawaki, Y. Takahashi and T. Tatsuma, J. Phys. Chem. C, 2013, 117, 5901-5907.

27 T. Kawawaki, Y. Takahashi and T. Tatsuma, Nanoscale, 2011, 3, 2865-2867.

28 M. Fleischmann, P. J. Hendra and A. J. McQuillan, Chem. Phys. Lett., 1974, 26, 163-166.

29 S. Nie and S. R. Emory, Science, 1997, 275, 1102-1106.

30 K. Kneipp, Y. Wang, H. Kneipp, L. T. Perelman, I. Itzkan, R. R. Dasari and M. S. Feld, Phys. Rev. Lett., 1997, 78, 1667-1670.

31 I. Freitag, C. Beleites, S. Dochow, J. H. Clement, C. Krafft and J. Popp, Analyst, 2016, 141, 5986-5989.

32 L. A. Austin, S. Osseiran and C. L. Evans, Analyst, 2016, 141, 476-503.

33 S. K. Jha, Y. Ekinci, M. Agio and J. F. Löffler, Analyst, 2015, 140, 5671-5677.

34 S. Polisetti, A. N. Bible, J. L. Morrell-Falvey and P. W. Bohn, Analyst, 2016, 141, 2175-2182.

35 O. Alharbi, Y. Xu and R. Goodacre, Analyst, 2015, 140, 59655970.

36 J. P. Smith, O. B. Sutcliffe and C. E. Banks, Analyst, 2015, 140, 4932-4948.

37 W. Xie and S. Schlücker, Chem. Commun., 2018, 54, 23262336.

38 B. H. Loo, Y. Tse, K. Parsons, C. Adelman, A. El-Hage and Y. G. Lee, J. Raman Spectrosc., 2006, 37, 299-304.

39 E. del Puerto, A. Cuesta, S. Sanchez-Cortes, J. V. GarciaRamos and C. Domingo, Analyst, 2013, 138, 4670-4676.

40 S. Schlücker, Angew. Chem., Int. Ed., 2014, 53, 4756-4795.

41 P. G. Etchegoin and E. C. Le Ru, Surface Enhanced Raman Spectroscopy ed. S. Schlücker, Wiley-VCH, Weinheim, 2011, pp. 1-37. 
42 L. Song, E. J. Hennink, I. T. Young and H. J. Tanke, Biophys. J., 1995, 68, 2588-2600.

43 E. V. Efremov, F. Ariese and C. Gooijer, Anal. Chim. Acta, 2008, 606, 119-134.

44 (a) N. Carl, S. Prèvorst, J. P. S. Fitzgerald and M. Karg, Phys. Chem. Chem. Phys., 2017, 19, 16348-16357; (b) P. G. Etchegoin and E. C. Le Ru, Surface Enhanced Raman Spectroscopy, ed. S. Schlücker, Wiley-VCH, Weinheim, 2011, pp. 1-37; (c) L. Tian, M. Su, F. Yu, Y. Xu, X. Li, L. Li, H. Liu and W. Tan, Nat. Commun., 2018, 9(1), 3642; (d) I. Bruzas, W. Lum, Z. Gorunmez and L. Sagle, Analyst, 2018, 143, 3990-4008.

45 S. Becht, S. Ernst, R. Bappert and C. Feldmann, Chem. Unserer Zeit, 2010, 44, 14-23.

46 A. Liopo, S. Wang, P. J. Derry, A. A. Oraevsky and E. R. Zubarev, RSC Adv., 2015, 5, 91587-91593.

47 D. Pan and D.-L. Phillips, J. Phys. Chem. A, 1999, 103, 47374743.

48 Y. Sun and Y. Xia, Analyst, 2003, 128, 686-691.

49 (a) M. W. Meyer and E. A. Smith, Analyst, 2011, 136, 35423549; (b) P. G. Etchegoin and E. C. Le Ru, Surface Enhanced Raman Spectroscopy ed. S. Schlücker, Wiley-VCH, Weinheim, 2011, pp. $47-50$.

50 (a) M. K. Corbierre and R. B. Lennox, Chem. Mater., 2005, 17, 5691-5696; (b) Á. I. López-Lorente, M. Laura Soriano and M. Valcárcel, Microchim. Acta, 2014, 181, 1789-1796.
51 (a) U. Rösch, S. Yao, R. Wortmann and F. Würthner, Angew. Chem., Int. Ed., 2006, 45, 7026-7030; (b) L. Zhang and J. M. Cole, J. Mater. Chem. A, 2017, 5, 19541-19559.

52 G. Ruderman, E. R. Caffarena, I. G. Mogilner and E. J. Tolosa, J. Solution Chem., 1998, 27, 935-948.

53 (a) M. R. K. Ali, B. Snyder and M. A. El-Sayed, Langmuir, 2012, 28, 9807-9815; (b) R. Parveen, J. F. Gomes, S. Ullah, J. J. S. Acuña and G. Tremiliosi-Filho, J. Nanopart. Res., 2015, 17, 418.

54 X. Ma, M.-C. Wang, F. You, J. Feng and X. Zhao, J. Alloys Compd., 2015, 649, 617-624.

55 B. Saute, R. Premasiri, L. Ziegler and R. Narayanan, Analyst, 2012, 137, 5082-5087.

56 E. Locatelli, I. Monaco and M. Comes Franchini, RSC Adv., 2015, 5, 21681-21699.

57 Z. Wang, S. Zong, J. Yang, C. Song, J. Li and Y. Cui, Biosens. Bioelectron., 2010, 26, 241-247.

58 A. Zoppi, S. Trigari, G. Margheri, M. Muniz-Miranda and E. Giorgetti, RSC Adv., 2015, 5, 8523-8532.

59 S. Fateixa, M. Wilhelm, A. M. Jorge, H. I. S. Nogueira and T. Trindade, J. Raman Spectrosc., 2017, 48, 795-802.

60 K. D. Shim and E.-S. Jang, Bull. Korean Chem. Soc., 2018, 39, 936-940.

61 O. Olea-Mejía, M. Fernández-Mondragón, G. Rodríguez-de la Concha and M. Camacho-López, Appl. Surf. Sci., 2015, 348, 66-70. 